\title{
A GWAS Identified a Major QTL for Resistance to Fusarium Wilt (Fusarium Oxysporum f. sp. Vasinfectum) Race 4 in a MAGIC Population of Upland Cotton and a Meta-Analysis of QTLs for Fusarium Wilt Resistance
}

Yi Zhu

New Mexico State University

Gregory N. Thyssen

USDA-ARS-SRRC: USDA-ARS Southern Regional Research Center

Abdelraheem Abdelraheem

New Mexico State University

Zonghua Teng

New Mexico State University

David D. Fang

USDA-ARS-SRRC: USDA-ARS Southern Regional Research Center

Johnie N. Jenkins

USDA-ARS

Jack C. McCarty

USDA-ARS

Tom Wedegaertner

Cotton Inc

Kater Hake

Cotton Inc

Jinfa Zhang ( $\nabla$ jinzhang@nmsu.edu )

New Mexico State University https://orcid.org/0000-0002-3821-1490

Research Article

Keywords: Upland cotton, Fusarium wilt, Race 4, MAGIC, RILs, SNPs, GWAS

Posted Date: January 27th, 2022

DOI: https://doi.org/10.21203/rs.3.rs-873841/v1 
License: (c) (i) This work is licensed under a Creative Commons Attribution 4.0 International License. Read Full License 


\section{Abstract}

Numerous studies have been conducted to investigate the genetic basis of Fusarium wilt (FW) resistance using bi-parental and association mapping populations in cotton. In this study, a multi-parent advanced generation inter-cross (MAGIC) population of 550 recombinant inbred lines (RILs), together with their 11 Upland cotton (Gossypium hirsutum) parents, was used to identify QTLs for FW race 4 (FOV4) resistance. Among the parents, Acala Ultima, M240, and Stoneville 474 were the most resistant, while Deltapine Acala 90, Coker 315, and Stoneville 825 were the most susceptible. Twenty-two MAGIC lines were consistently resistant to FOV4. Through a genome-wide association study (GWAS) based on 473,516 polymorphic SNPs, a major FOV4 resistance QTL within a narrow region on chromosomes D02 was detected, allowing identification of 14 candidate genes. Additionally, a meta-analysis of 101 published FW resistance QTLs showed a D subgenome and individual chromosome bias and no correlation between homeologous chromosome pairs. This study represents the first GWAS study using a largest genetic population and the most comprehensive meta-analysis for FW resistance in cotton. The results illustrated that 550 lines are not enough for high resolution mapping to pinpoint a candidate gene, and experimental errors in phenotyping cotton for FW resistance further compromise the accuracy and precision in QTL localization and identification of candidate genes. This study identified FOV4 resistant parents, MAGIC lines, and the first major QTL for FOV4 resistance, providing useful information for developing FOV4 resistant cultivars and further genomic studies towards identification of causal genes for FOV4 resistance in cotton.

\section{Key Message}

A Major QTL conferring resistance to Fusarium wilt Race 4 in a narrow region of chromosome D02 was identified in a MAGIC population of 550 RILs of Upland cotton.

\section{Introduction}

Fusarium wilt of cotton, caused by soilborne pathogen Fusarium oxysporum f. sp. vasinfectum Atk. Sny \& Hans (FOV), is a devastating disease that can lead to significant yield losses in most cotton-producing regions of the world. In the US, FW caused annual cotton yield loss ranging from 0.19 to $1.36 \%$ (Blasingame and Patel 2013). The pathogen infects cotton roots and colonizes the vascular system, causing plant wilting, leaf chlorosis and necrosis, stunting, vascular discoloration, defoliation and plant death (Zhang et al. 2015a; Sanogo and Zhang 2016). FOV has been characterized into eight pathogenic races (designated race 1 to 8 ) based on DNA sequence analysis and pathogenicity tests (Cianchetta et al. 2015; Davis et al. 2006). FOV race 4 (FOV4) is an emerging pathogen that threatens cotton (Gossypium spp.) production in the west and southwest and potentially the entire US Cotton Belt (Kim et al. 2005; Hutmacher et al. 2013; Halpern et al. 2018; Zhu et al. 2020). It is highly virulent to both Pima (G. barbadense L.) and Upland (G. hirsutum L.) cotton and infects cotton in the early seedling growth stages under field conditions, causing seedling wilt and deaths in the absence of nematodes in many cotton fields. It has been a significant problem in California for the past 20 years (Kim et al. 2005) and has since 
been reported in El Paso, Texas in 2017 (Halpern et al. 2018; Bell et al. 2019) and Las Cruces, New Mexico in 2019 (Zhu et al. 2020; Zhu et al. 2021). Four different genotypes of FOV4 isolates were recently identified through a multiplex PCR method based on the presence of Tfo1 (T type), Tfo1/MULE (MT type) and Tfo1/MITE (MiT type) or absence of above insertions ( $\mathrm{N}$ type) in the PHO gene encoding for phosphate permease (Bell et al. 2019). Managing the disease is extremely difficult because FOV can persist in soil for many years or decades, and the most and only effective way to manage FOV4 is to breed and utilize resistant cotton cultivars (Zhang et al. 2015a; Sanogo and Zhang 2016).

Breeding for resistant cotton cultivars to FW is challenging. Many efforts have been made to enhance FW resistance in cotton germplasms or commercial cultivars in the US (Bird 1982; Kappelman and Bird 1981; Thaxton and El-Zik 1998, 2003, 2004a,b; Zhang et al. 2015a). For example, through the multi-adversity resistance (MAR) cotton system in Texas, progressive improvements in resistance to FW were made in the MAR germplasms (Thaxton and El-Zik 1998, 2003, 2004a,b). In Arkansas, numerous germplasm lines and several cultivars with FW resistance including Arkot 518 (Smith 1988) and H1330 (Bourland 1996) were released through a modified MAR system. Auburn University has also released cotton germplasms or commercial cultivars that possess some levels of FW resistance through testing in the National Fusarium Wilt Nursery. As a result, breeding for FW resistance has been substantially enhanced in many cotton cultivars.

However, most commercial cultivars and breeding lines which were developed in non-FOV infested fields are susceptible to FW. The response to FOV infections in cotton has been treated as both a qualitative and a quantitative trait to study the genetic basis of resistance using traditional Mendelian and quantitative genetic approaches (Zhang et al. 2015a). In the 1930-40s, India reported that resistance to race 4 was determined by two complementary dominant genes and a third inhibitory gene in G. arboreum and one dominant gene in G. herbaceum (cited by Smith and Dick 1960). Studies in other countries showed resistance to race 3 and 6 was controlled by a major gene (Fahmy 1934; Netzer 1982; Zhang et al. 2015). In the US, a major dominant resistant gene (FOV1) to race 1 was confirmed in Pima S-7 (G. barbadense) and later mapped on chromosome D07 (c16) using simple sequence repeat (SSR) markers (Wang and Roberts 2006; Ulloa et al. 2011). A major resistance gene (FOV4) conferring resistance to FOV4 was identified in resistant Pima S-6 and mapped to chromosome D02 (c14) based on SSR markers (Ulloa et al. 2013). Also, two major RKN resistance genes (dominant Mi1 and additive Mi2) were identified and mapped to chromosomes A11 (c11) and D02 (c14), respectively, based on SSR markers (Niu et al. 2007; Gutierrez et al. 2010; He et al. 2014). Because RKN can increase the incidence of FW in both resistant and susceptible cultivars, it may be possible to breed for FW resistance by breeding solely for high RKN resistance. However, it is currently unknown if FOV4 and one of the two RKN resistance genes are located within the same chromosomal region on D02 (c14). In China, two major dominant resistance genes $\left(F w_{1}\right.$ and $\left.F w_{2}\right)$ to FOV race 7 were identified in resistant Upland cottons (Feng et al. 1998).

Subsequently, a dominant resistance gene $\left(F W^{R}\right)$ on chromosome D03 (c17) was identified using SSR markers in two $F_{2: 3}$ populations (Wang et al. 2009). Zhu et al. (2010) mapped a single dominant resistance gene on chromosome D11 (c21) in a G. barbadense cross of susceptible Xinhai $21 \times$ highly 
resistant HK 237 based on SSR markers. The two major resistance genes for race 1 (on D07 from Pima S7) and race 4 (on D02 from Pima S-6) are different from the two major resistance genes for race 7 (one on D03 from Upland and another on D11 from G. barbadense).

The response to FOV infection in cotton has also been treated as a quantitative trait which is controlled by multigenes with small effects. Quantitative trait loci (QTL) mapping is a powerful tool that has been widely used to dissect the genetic changes of complex quantitative traits in cotton. Identifying QTLs and dissecting the genetic basis of FOV resistance are important for marker-assisted selection (MAS) in cotton breeding. To date, many types of molecular markers, such as restriction fragment length polymorphism (RFLP), amplified fragment polymorphism (AFLP), simple sequence repeat (SSR), and single nucleotide polymorphisms (SNP) have played an important role in detecting resistance quantitative trait locus (QTL) location or resistance genes for different races of FOV using biparental and association populations (Zhang et al. 2015a). In a meta-analysis, 33 QTLs mapped for FW resistance in cotton was summarized by Zhang et al. (2015b) from previous published papers based on early segregating populations and recombinant inbred lines (RILs). Based on a more recent meta-analysis, Abdelraheem et al. (2017) increased the number of QTLs reported for FW resistance to 47, and most FOV resistance QTLs were located on five chromosomes, i.e., A06 (c6), D02 (c14), D03 (c17), D04 (c22), and D06 (c25). Using a RIL population from an interspecific cross of Pima S-7 (resistant to FOV1 and susceptible to FOV4) $\times$ Acala NemX (susceptible to FOV1 and tolerant to FOV4 in the greenhouse) with 367 SSR markers, Wang et al. (2018) detected six major QTLs on chromosomes A01 (c1), A02 (c2), A12 (c12), D01 (c15), and D11 (c21) for FOV1 resistance and two major QTLs on D02 (c14) and D03 (c17) for FOV4 resistance. Most recently, 13 FOV4 resistance QTLs were identified on six chromosomes, i.e., A08 (c8), D02 (c14), D03 (c17), D05 (c19), D07 (c16), and D13 in the US Upland cotton with 25,677 SNP markers through a genome-wide association study (GWAS) of 367 US Upland accessions (Abdelraheem et al. 2020a). Seven QTLs for FOV4 resistance were mapped on six chromosomes (D02/c14, D03/c17, D05/c19, D06/c25, D08/c24, and D11/c21) using 163 RILs of a G. barbadense cross from FOV4-resistant Pima S-6 × susceptible 89590 with 403 SSR markers (Abdelraheem et al. 2020b). Although many QTLs conferring FW resistance have been mapped on all chromosomes except for a few chromosomes including A04 (c4) and D10 (c20), major effect resistance QTLs are located on only a few chromosomes (Zhang et al. 2015a,b; Abdelraheem et al. 2017).

Based on biparental populations, a large number of QTLs for FW resistance have been reported from the linkage analysis, and many QTLs may be commonly detected across multiple tests in the same population or across different populations (Zhang et al. 2015a,b; Abdelraheem et al. 2017). However, limited by low genetic diversity and marker density on a genetic map, linkage analysis can only detect and map a few QTLs in each genetic population (Huang et al. 2017; Li et al. 2017; Islam et al. 2016). Furthermore, limited numbers of markers and relatively small population sizes also reduce the resolution power to fine map FW resistance QTLs. In recent years, genome-wide association study (GWAS) as a useful and powerful tool to detect QTLs has been widely used in QTL mapping in many plant species (Zhao et al. 2011; Atwell et al. 2010; Kump et al. 2011; Zhao et al. 2015). In cotton, GWAS has also been widely used in QTL mapping for important economic traits, such as disease resistance traits 
(Abdelraheem et al. 2020a; Zhao et al. 2021), fiber quality traits (Islam et al. 2015; Nie et al. 2016) and yield components (Liu et al. 2018; Qin et al. 2015). Abdelraheem et al. (2020a) conducted a GWAS using high-density genotyping with the CottonSNP63K array in 376 US Upland cotton accessions and detected two consistent QTL clusters on c16 (D07) and c19 (D05) for resistance to both Verticillium wilt (VW) and FOV4 in the greenhouse studies. However, reports of GWAS for FOV4 resistance in Upland cotton are still limited. As compared to linkage mapping, GWAS offers a higher resolution with relatively higher marker coverage on genome and is more cost-effective for detecting important QTLs or genes associated with complex traits (Huang et al. 2018). With the use of high-throughput next-generation sequencing technology, such as genotyping by sequencing (GBS), high density of SNP markers were identified and used in Upland cotton (Islam et al. 2015) to improve the resolution and accuracy of the QTL mapping. However, the mapping population size should also be sufficiently large to delineate a QTL to a narrow chromosome region. This will facilitate the identification of candidate genes underlying the natural variation in FW resistance, leading to the cloning of FW resistance genes.

In the US, early FW resistant cultivars developed were lower yielding with deficiencies in many other agronomic traits in non-infested fields than the best agronomically acceptable but less resistant cultivars. However, many moderately or highly FW (not caused by FOV4) resistant cotton cultivars with good quality have been developed since the late 1960s (Zhang et al. 2015a). Therefore, representative Upland cotton cultivars can be used to develop a multi-parent advanced generation inter-cross (MAGIC) population to capture more genetic variation for breeding and genetic and genomic studies. In this study, a GWAS was conducted for FOV4 resistance in a MAGIC population consisting of 550 RILs created from 11 US Upland cotton cultivars using a total of 473,516 SNP markers developed through whole genome sequencing. The aim of this study was to identify candidate QTL regions and genes involved in FOV4 resistance and provide information on the genetic mechanisms of resistance to FOV4 in Upland cotton. This MAGIC population has been recently used to identify QTL and candidate genes for fiber quality traits, resistance to RKN and VW and tolerance to drought and salt (Islam et al. 2016; Thyssen et al. 2019; Naoumkina et al. 2019; Wubben et al. 2019; Zhang et al. 2020a; Abdelraheem et al. 2020a).

\section{Materials And Methods}

In this study, a MAGIC population, consisting of 550 RILs designated MG1 to MG550, was developed from a random mated Upland population of 11 parents (Jenkins et al. 2008). The 11 parents represented diverse Upland cotton genetic backgrounds from major cotton seed companies and two public breeding programs in the US and also differed in FW resistance (Table 1). The MAGIC population used in this study was created through 5 generations of random-mating followed by 6 generations of self-pollination (Jenkins et al. 2008), and the development of this MAGIC population was described in detail by Islam et al. (2016). 
Table 1

Parental lines of Upland cotton (Gossypium hirsutum) used to develop the MAGIC population of 550 recombinant inbred lines (RILs).

\begin{tabular}{|llll|}
\hline Parent & $\begin{array}{l}\text { Year of } \\
\text { release }\end{array}$ & Pedigree & Backbone source \\
\hline Acala Ultima & 1997 & NMB4164/NMB2724 & Acala \\
\hline Coker 315 & 1979 & Coker 310/Coker 8103 & DP 15 \& Coker 100 \\
\hline $\begin{array}{l}\text { Deltpine Acala } \\
90\end{array}$ & 1981 & $\begin{array}{l}\text { 6022-4-4/DP16//John Cotton } \\
\text { Polycross/DP16 }\end{array}$ & $\begin{array}{l}\text { DP 15, STV 7, \& } \\
\text { Acala }\end{array}$ \\
\hline FberMax 966 & 2000 & $88001 / 83055-33$ & Acala \\
\hline M-240RNR & 1989 & Auburn 634 RNR//DP 61 & DP 15 \\
\hline $\begin{array}{l}\text { Paymaster HS } \\
26\end{array}$ & 1983 & Acala SJ-4/5B9-184 & C6TE/NMB3080 \\
\hline $\begin{array}{l}\text { Phytogen PSC } \\
\text { 355 }\end{array}$ & 2002 & Acala 1517-88/DES 949 & DP 15 \& STV 7 \\
\hline Stoneville 474 & 1994 & STV 453/DES 119 & STV 7 \\
\hline Stoneville 825 & 1981 & STV 7A/Meyer 76-4 & STV 7 \\
\hline SureGrow 747 & 1999 & DP 50/3*DES 119 & DP 15 \& STV 7 \\
\hline Tamcot Pyramid & 2001 & Tamcot Sphinx/CD3HGCBU8S-1-91 & $\begin{array}{l}\text { Tamcot SP-21 } \\
\text { (MAR) }\end{array}$ \\
\hline
\end{tabular}

To evaluate the population for FOV4 resistance, two tests (Test 1 and 2) each with 2 replications (with 10 seedlings for each genotype per replication) were arranged in a randomized complete block design (RCBD) in a greenhouse at the Fabian Garcia Research Center, New Mexico State University, Las Cruces, NM, USA. The seed of each genotype was planted in a 10-cm plastic pot with 10 seed per pot (five hills per pot, two seed per hill) in 2018 at two different planting and evaluation dates for the two tests (May to July for Test 1 and September to October for Test 2). The temperature in the greenhouse ranged from 22 to $35^{\circ} \mathrm{C}$. The potting soil used was Miracle-Gro Moisture Control Potting Mix $2 \mathrm{CF}$ (Scotts Co., Marysville, $\mathrm{OH}, \mathrm{USA})$. An established inoculation method was used to inoculate cotton seedlings with spores from a virulent local FOV4 isolate, FW-JF-1A (Zhu et al. 2019; Zhu et al. 2021; Zhang et al. 2020c). FW-JF-1A was identified to be FOV4 based on a FOV4-specific PCR, and it belonged to the MT genotype based on a multiplex PCR (Bell et al. 2019). A total of $10 \mathrm{ml}$ of $1 \times 10^{6}$ spores $\mathrm{ml}^{-1}$ conidial suspension of FOV4 were inoculated to emerged seedlings with 1-2 true leaf in each pot (10 plants $\left.\operatorname{pot}^{-1}\right)$. The inoculum was pipetted onto the soil surface with no root wounding, and pots were lightly watered immediately after inoculation. Fungal culture, spore quantification, and inoculation techniques followed Zhang et al. (2021).

The response of the cotton seedlings to FOV4 infections was monitored daily and evaluated at 30 days after inoculation (DAI) using our previously established protocol with a $0-5$ rating scale for foliar disease 
severity ratings (DSR) on an individual plant basis (Zhang et al. 2020b), as follows:

0 no symptom

1 one wilted cotyledon

2 two wilted cotyledons or two cotyledons abscised

3 first true leaf wilted or three leaves (including two cotyledons) abscised

4 whole plant wilted or more than three leaves abscised

5 dead plant

The disease incidence (DI, percentage of infected plants with symptoms) and average DSR (the sum of the DSR divided by the number of plants) were calculated on a replication basis for each genotype. Since the two tests were from two different greenhouses, plot data were then subjected to a combined analysis of variance (ANOVA) for the two tests using SAS 9.3 (SAS Institute Inc., Cary, NC, USA). PROC MIXED statistical procedure was used to determine the statistical significance of various sources of variation, in which genotype was treated as a fixed effect, and test and replication as a random effect. Broad-sense heritability $\left(h^{2}\right)$ in each test and across tests was estimated from variance components (Abdelraheem et al. 2018).

The genome of the MAGIC population was sequenced for SNP identification and GWAS for DSR-based FW resistance, and the details of methodology were described elsewhere for the same MAGIC population (Thyssen et al. 2019). Briefly, to genotype the MAGIC population, a whole genome 100-150 bp paired-end sequencing (Illumina) was used to sequence parents at 20x and RILs at $3 \times$ genome coverage by Novogene Corporation (Chula Vista, CA, USA) using Illumina HiSeq 2500. Sequence reads were aligned to the NBI G. hirsutum cv TM-1 reference genome (Zhang et al. 2015b) with updates using GSNAP software (Wu and Nacu 2010) for SNP identification using samtools and bcftools software (Li et al. 2009). As a result, 473,516 SNPs were identified. For GWAS, GAPIT software with default parameters (Lipka et al. 2012) was used to determine the association between SNPs and FOV4 resistance using a mixed linear model (Zhang et al. 2010). In this study, a QTL was declared when 4 significant SNPs at $1 \times 10^{-3}$ were detected within a $6 \mathrm{Mb}$ region. For a multiple comparison adjustment, a false discovery rate (FDR) adjusted P-value (i.e., the $P$ value at 0.05 divided by the total number of 473,516 SNPs) was also calculated (Benjamini and Hochberg 1995). A QTL cluster was declared when multiple QTL were overlapped or were within a 15-40 Mb region.

To identify candidate genes for FOV4 resistance, annotated genes that were within the QTL regions from the GWAS were retrieved from the GFF files of the G. hirsutum cv TM-1 reference genome (Zhang et al. 2015; Hu et al. 2019; Wang et al. 2019). To search for candidate genes, the annotated genes within the QTL regions were filtered based on relevant gene ontology terms of Arabidopsis orthologs, including response to fungus or biotic stimulus (Berardini et al. 2015). These candidate genes were then examined 
for non-synonymous variants. A SNP-index for each SNP within a QTL region was further calculated for the most FOV4-resistant RIL group and the most FOV4-susceptible RIL group separately as the frequency of a SNP allele in each group. The difference in the SNP frequency between the two groups is called delta (SNP-index), i.e., D(SNP-index) (Takagi et al. 2013). If a SNP is not linked to a QTL, D(SNP-index) is close to zero. To assess if the functionally relevant genes with sequence variation within the QTL regions were differentially expressed, root tissue or germinating seed- specific RNA-seq data for these genes were retrieved from ccNET (http://structralbiology.cau.edu.cn.gossypium) (You et al. 2016). Then, genes that had D(SNP-index) equal to or higher than 0.3 and were expressed in relevant tissues and showed responses to the biotic stress stimuli were identified as candidate genes.

\section{Results}

\section{Genetic difference of FOV4 resistance among the 11 founder parents}

On a genotype basis, DI ranged from 16.7 to $100 \%$ in Test 1 and from 11.8 to $87.5 \%$ in Test 2, while DSR ranged from 0.2 to 3.3 in Test 1 and from 0.2 to 2.6 in Test 2, among the 11 founder parents. Significant genotypic variation in FOV4 resistance was detected (Table 2). Tests 1 and 2 showed relatively consistent results in FOV4 resistance among the 11 founder lines, as indicated by a significant positive correlation in DSR between the two tests $(r=0.715, P<0.05)$. As shown in Table 2, when Deltapine Acala 90 was used as the susceptible check because of its highest average DSR (2.84) and DI among the 11 parents, Acala Ultima, M-240RNR, and Stoneville 474 were significantly lower in DSR in both tests and across the two tests (0.09-0.78), and they were therefore considered as the resistant parent group. In addition, FiberMax 966, Paymaster HS 26, and SureGrow 747 had significantly lower DSR in Test 1 and also on average across the two tests (0.64-1.26). On the other hand, the other four parental lines (Coker 315, Phytogen PSC 355, Stoneville 825, and Tamcot Pyramid) were equally susceptible to FOV4 as the susceptible check in both tests and on average (1.74-2.59), and therefore, these four genotypes were considered as the susceptible parent group. 
Table 2

Fusarium wilt (Fusarium oxysporum f. sp. vasinfectum) race 4 resistance of 11 founder Upland cotton lines (Gossypium hirsutum) used in the development of the MAGIC population, evaluated in the greenhouse, Las Cruces, NM, USA, 2018.

\begin{tabular}{|c|c|c|c|c|c|c|}
\hline \multirow[t]{2}{*}{ Parent } & \multicolumn{3}{|l|}{ DSR } & \multicolumn{3}{|c|}{ Incidence (\%) } \\
\hline & Test 1 & Test 2 & Mean & Test 1 & Test 2 & Mean \\
\hline Acala Ultima & $0.50 *$ & $0.20 *$ & $0.35^{\star}$ & 50.00 & $20.00^{\star}$ & $35.00 *$ \\
\hline Coker 315 & 2.30 & 2.19 & 2.25 & 92.86 & 66.67 & 79.76 \\
\hline Deltpine Acala 90 (CK) & 3.30 & 2.38 & 2.84 & 100.00 & 81.25 & 90.63 \\
\hline FberMax 966 & $0.17 \star$ & 1.11 & $0.64^{\star}$ & $16.67^{\star}$ & $39.29 *$ & $27.98 *$ \\
\hline M-240RNR & $1.28^{*}$ & $0.29 *$ & $0.78^{*}$ & 90.00 & $14.29 *$ & $52.14^{\star}$ \\
\hline Paymaster HS 26 & $0.63^{*}$ & 1.90 & $1.26^{\star}$ & 46.43 & 65.97 & 56.20 \\
\hline Phytogen PSC 355 & 2.50 & 1.29 & 1.90 & 100.00 & 50.79 & 75.40 \\
\hline Stoneville 474 & $0.00 *$ & $0.18^{*}$ & $0.09 *$ & $0.00 *$ & $11.81^{\star}$ & $5.90 *$ \\
\hline Stoneville 825 & 2.53 & 2.64 & 2.59 & 100.00 & 87.50 & 93.75 \\
\hline SureGrow 747 & $0.83^{*}$ & 0.94 & $0.89 *$ & 75.00 & $37.50^{\star}$ & 56.25 \\
\hline Tamcot Pyramid & 2.10 & 1.38 & 1.74 & 80.00 & 49.21 & 64.60 \\
\hline LSD (0.05) & 1.76 & 1.95 & 1.36 & 69.47 & 43.03 & 37.46 \\
\hline
\end{tabular}

These 11 cultivars were developed under non-FOV4 infested field conditions in a span of 24 years between 1979 and 2002. Based on a pedigree analysis (Table 1), seven parents can trace their parentages to Deltapine (DP) 15 and/or Stoneville (ST) 7, while three parental lines had Acala or New Mexico germplasm in their parentages. However, Tamcot Pyramid was developed in the MAR program and its parentage could not be traced to any specific germplasm lines. It appears that the genetic difference in FOV4 resistance detected in this study was not due to the inclusion of the backbone germplasm lines (DP 15 and ST 7) in their pedigrees. For example, the three more resistant lines- M240RNR, ST 474, and SureGrow 747 and the four more susceptible lines- Coker 315, DP Acala 90, Phytogen PSC 355, and ST 825, all had DP 15 and/or ST 7 in their pedigrees. The more resistant Acala Ultima and Paymaster HS 26 and the more susceptible DP Acala 90 and FiberMax 966 all had Acala or New Mexico germplasm in their parentages. Tamcot Pyramid did not show any FOV4 resistance, although it was developed in the MAR program for enhancement of cotton resistance to VW, FW and RKN. Therefore, the genetic variation in FOV4 resistance within the 11 founder parents may be the consequence of random recombination and fixation of resistance genes and alleles in breeding under 
non-selective conditions for FOV4 resistance. In this study, the existence of the quantitative genetic variation in FOV4 resistance among the 11 founder parents allowed the following analysis of the genetic and genomic basis of FOV4 resistance in the MAGIC population derived from them.

\section{Analysis of variance and broad-sense heritability estimates for FOV4 resistance in the MAGIC population}

As shown in Table 3, a combined ANOVA for the entire MAGIC population indicates that DI and DSR were significant (at $P<0.001$ ) in test, genotype, and also genotype $\times$ test interaction. Therefore, a further analysis was performed on an individual test basis. In both Tests 1 and 2, DI and DSR showed a significant genotypic variation (at $P<0.001$, except for $\mathrm{DI}$ in Test 1 at $P<0.05$ ). The two tests were grown in the same greenhouse during different time periods with two different inoculum preparations and inoculations, in addition to other uncontrollable factors in greenhouse and crop management. These factors may have contributed to genotype $\times$ test interactions, as seen from different results between the two tests for some parental genotypes (Table 2). 
Table 3

Analysis of variance (mean square) of Fusarium wilt (Fusarium oxysporum f. sp. vasinfectum) race 4 resistance in the MAGIC population of 550 recombinant inbred lines (Gossypium hirsutum) tested two replicated tests in the greenhouse, Las Cruces, NM, USA.

\begin{tabular}{|c|c|c|}
\hline Source & DSR & Incidence (\%) \\
\hline \multicolumn{3}{|l|}{ Combined } \\
\hline Test & $46.51^{\star \star \star}$ & $404820.86^{\star \star \star}$ \\
\hline Genotype & $1.35^{\star \star \star}$ & 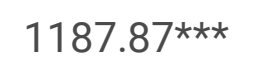 \\
\hline Genotype $\times$ Test & $1.28^{\star \star \star}$ & 1073.11 *** \\
\hline Error & 0.88 & 793.19 \\
\hline$h^{2}$ & 0.605 & 0.599 \\
\hline \multicolumn{3}{|l|}{ Test 1} \\
\hline Replication & $9.33^{\star \star}$ & $907.67 * \star$ \\
\hline Genotype & $0.99 * * \star$ & 2712.70* \\
\hline Error & 0.66 & 659.38 \\
\hline$h^{2}$ & 0.600 & 0.804 \\
\hline \multicolumn{3}{|l|}{ Test 2} \\
\hline Replication & $21.68 * \star \star$ & $2298.50 \mathrm{~ns}$ \\
\hline Genotype & $1.70^{\star \star \star}$ & $1396.68^{\star \star \star}$ \\
\hline Error & 0.99 & 893.20 \\
\hline$h^{2}$ & 0.632 & 0.601 \\
\hline
\end{tabular}

Because DSR takes into consideration of incidence and leaf symptom severity including plant death, it was therefore further used to quantitatively measure the overall FOV4 resistance in this study. Broadsense heritability estimates for DSR in the two tests were similar, ranging from 0.60 in Test 1 to 0.63 in Test 2, and the estimate was 0.62 in a combined ANOVA from the two tests (Table 3 ). The results indicate that approximately $60 \%$ of the phenotypic variation in FOV4 resistance was due to genetic variation in this MAGIC population. Therefore, a further detection of genetic factors for FOV4 resistance was warranted.

Genetic difference of FOV4 resistance in the MAGIC population of 550 RILs 
In the MAGIC population, the DI ranged from 0 to $100 \%$ in both tests with an average of 89.4 and $83.6 \%$ in Tests 1 and 2, respectively; and the DSR ranged from 0 to 4.2 with an average of 1.8 in Test 1 and from 0 to 4.9 with an average of 1.5 in Test 2 . An average of only 1.0 and $5.0 \%$ plant mortality was observed in Tests 1 and 2, respectively. Averaging across the two tests, many RILs had significantly and consistently lower DSR than the susceptible check (DP Acala 90) in both tests, and Table 4 shows 22 of them. As a comparison, the table also lists 23 most susceptible lines. It appears that the resistance level of the most resistant RILs was within the level of the most resistant parents (Table 2), while the most susceptible RILs were more susceptible than the most susceptible parent (DP Acala 90). The above results suggest that transgressive segregation toward susceptibility occurred during the intermating process among the progeny from the hybrids of the 11 founders. However, because responses of some of the RILs are likely different to FOV4 infections under low temperature conditions, RILs with significantly higher FOV4 resistance than the parents may be identified. 
Table 4

Most resistant and most susceptible lines (Gossypium hirsutum) in responses to Fusarium wilt (Fusarium oxysporum f. sp. vasinfectum) race 4 infections in the MAGIC population based on disease severity ratings (DSR).

\begin{tabular}{|lllllllll|}
\hline Line & Test 1 & Test 2 & Mean & Line & Test 1 & Test 2 & Mean \\
\hline Most resistant lines & & \multicolumn{5}{l}{ Most susceptible lines } \\
\hline MG150 & 1.00 & 0.00 & 0.50 & MG64 & 2.25 & 4.50 & 3.38 \\
\hline MG202 & 1.00 & 0.17 & 0.59 & MG32 & 2.24 & 3.46 & 2.85 \\
\hline MG207 & 0.17 & 0.89 & 0.53 & MG427 & 2.00 & 3.42 & 2.71 \\
\hline MG217 & 0.75 & 0.31 & 0.53 & MG72 & 2.05 & 3.75 & 2.90 \\
\hline MG22 & 0.88 & 0.93 & 0.91 & MG326 & 2.03 & 3.55 & 2.79 \\
\hline MG236 & 0.75 & 0.91 & 0.83 & MG444 & 3.67 & 1.94 & 2.81 \\
\hline MG272 & 0.50 & 0.25 & 0.38 & MG320 & 4.00 & 2.75 & 3.38 \\
\hline MG274 & 0.60 & 0.19 & 0.40 & MG421 & 2.25 & 2.36 & 2.36 \\
\hline MG283 & 0.43 & 0.76 & 0.60 & MG388 & 3.25 & 2.93 & 3.09 \\
\hline MG286 & 0.83 & 0.93 & 0.88 & MG108 & 3.58 & 1.93 & 2.76 \\
\hline MG313 & 0.67 & 0.79 & 0.73 & MG305 & 1.92 & 2.53 & 2.23 \\
\hline MG374 & 0.80 & 0.37 & 0.59 & MG516 & 3.08 & 2.60 & 2.84 \\
\hline MG398 & 0.33 & 0.69 & 0.51 & MG399 & 3.25 & 3.36 & 3.31 \\
\hline MG407 & 0.34 & 0.67 & 0.51 & MG513 & 1.75 & 3.25 & 2.50 \\
\hline MG416 & 0.20 & 0.68 & 0.44 & MG435 & 2.67 & 3.29 & 2.98 \\
\hline MG419 & 0.29 & 0.67 & 0.48 & MG288 & 2.25 & 3.81 & 3.03 \\
\hline MG425 & 0.25 & 0.69 & 0.47 & MG465 & 1.92 & 3.96 & 2.94 \\
\hline MG426 & 0.17 & 0.00 & 0.09 & MG67 & 2.70 & 4.17 & 3.44 \\
\hline MG498 & 0.00 & 0.21 & 0.11 & MG390 & 3.00 & 4.13 & 3.57 \\
\hline MG528 & 1.00 & 0.20 & 0.60 & MG123 & 2.19 & 3.42 & 2.81 \\
\hline MG547 & 0.20 & 0.42 & 0.31 & MG31 & 3.25 & 2.20 & 2.73 \\
\hline MG60 & 0.14 & 0.96 & 0.55 & MG394 & 3.54 & 2.07 & 2.81 \\
\hline Acala 90 (S) & 3.30 & 2.38 & 2.84 & MG101 & 2.33 & 3.05 & 2.69 \\
\hline & & & & LSD (0.05) & 1.76 & 1.95 & 1.36 \\
\hline
\end{tabular}




\section{Qtls Mapped For Fov4 Resistance In The Magic Population}

Mean DSRs for each MAGIC line from Tests 1 and 2 and the average from the two tests were used for GWAS based on 473,516 polymorphic SNP markers in this study. Based on means across the two tests, 8 QTLs including 2 (one each on A10 and A12) on the A subgenome and 6 QTLs (5 on D02 and 1 on D04) on the D subgenome were detected (Table 5, Fig. 2). In Test 1, 10 QTLs were detected, including 3 QTLs with one each on A06, A10 and A13 of the A subgenome and 7 QTLs on the D-subgenome ( 5 on D02 and one each on D03 and D11). Notably, qFOV4-D02-3a detected between the 0.7 and $1.2 \mathrm{Mb}$ region represented a major QTL with the highest delta(SNP-index) value and LOD score (Table 5, Fig. 2). In Test 2, 13 QTLs were detected, including 4 QTLs with one each on A05, A08, A12, and A13 of the A-subgenome and 9 QTLs with 6 on D02 and one each on D01, D11, and D13 of the D-subgenome. Three common QTLs were detected between Test 1 and the overall means across the two tests, while 3 QTLs were common between Test 2 and the overall means across the two tests. Therefore, a total of 6 common QTLs were detected between an individual test and the overall means across the two tests. Taken together, 23 QTLs (7 on the A-subgenome and 16 on the D-subgenome) for FOV4 resistance were detected on 12 of the 26 pairs of Upland cotton chromosomes. 
Table 5

QTL detected for Fusarium wilt (Fusarium oxysporum f. sp. vasinfectum) race 4 resistance based on severity disease ratings in the MAGIC population of 550 recombinant inbred lines (Gossypium hirsutum),

evaluated in two replicated tests with artificial inoculations in the greenhouse, Las Cruces, NM, USA.

$\begin{array}{llllllll}\text { QTL locus } & \text { Test } & \text { Chr } & \text { Start (bp) } & \text { End (bp) } & \text { Peak (bp) } & \begin{array}{l}\text { Mean } \\ \text { SNP } \\ \text { Index }\end{array} & \begin{array}{l}\log _{10} \\ \text { (p) }\end{array}\end{array}$

$\begin{array}{lllllllll}\begin{array}{l}\text { qFOV4- } \\ \text { A05-1 }\end{array} & \text { T2 } & \text { A05 } & 90,432,574 & 90,753,953 & 90,552,418 & 0.25 & 4.14 & 0.21\end{array}$

$\begin{array}{lllllllll}\text { qFOV4- } & \text { T1 } & \text { A06 } & 1,679,590 & 2,204,558 & 2,204,558 & 0.08 & 3.51 & 0.18\end{array}$

A06-1

$\begin{array}{lllllllll}\text { qFOV4- } & \text { T2 } & \text { A08 } & 90,521,160 & 90,636,368 & 90,600,982 & 0.01 & 3.45 & -0.15\end{array}$

A08-1

$\begin{array}{lllllllll}\text { qFOV4- } & \text { T1 } & \text { A10 } & 95,558,764 & 95,606,868 & 95,580,590 & 0.16 & 3.58 & 0.13\end{array}$

A10-1a

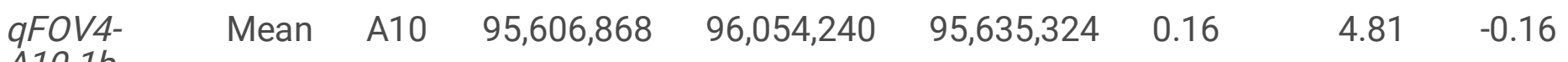

$A 10-1 b$

$\begin{array}{lllllllll}\text { qFOV4- } & \text { T2 } & \text { A12 } & 84,239,091 & 84,422,787 & 84,420,565 & 0.15 & 5.34 & -0.19\end{array}$

A12-1a

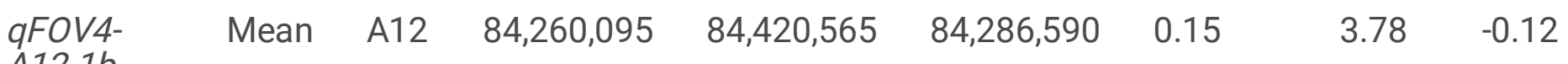

$A 12-1 b$

$\begin{array}{lllllllll}\text { qFOV4- } & \text { T1 } & \mathrm{A} 12 & 86,835,123 & 87,046,181 & 87,032,949 & 0.15 & 3.42 & 0.10\end{array}$

A12-2

$\begin{array}{lllllllll}\text { qFOV4- } & \text { T2 } & \mathrm{A} 13 & 59,513,985 & 59,961,534 & 59,745,124 & 0.11 & 3.29 & -0.21\end{array}$

A13-1

$\begin{array}{lllllllll}\text { qFOV4- } & \text { T2 } & \text { D01 } & 54,347,064 & 54,684,752 & 54,663,115 & 0.17 & 4.17 & 0.17\end{array}$

D01-1

$\begin{array}{lllllllll}\text { qFOV4- } & \text { T1 } & \text { D02 } & 247,093 & 409,056 & 409,056 & 0.11 & 5.79 & 0.18\end{array}$

D02-1

$\begin{array}{lllllllll}\text { qFOV4- } & \text { T1 } & \text { D02 } & 508,090 & 681,893 & 539,793 & 0.15 & 6.32 & -0.21\end{array}$

D02-2

$\begin{array}{lllllllll}\text { qFOV4- } & \text { T1 } & \text { D02 } & 714,520 & 1,249,921 & 933,851 & 0.35 & 9.64 & 0.28\end{array}$

D02-3a

$\begin{array}{lllllllll}\text { qFOV4- } & \text { Mean } & \text { D02 } & 731,052 & 1,344,425 & 979,730 & 0.33 & 4.12 & 0.13\end{array}$

$D 02-3 b$

$\begin{array}{lllllllll}\text { qFOV4- } & \text { T1 } & \text { D02 } & 1,303,697 & 1,526,555 & 1,303,697 & 0.33 & 6.69 & 0.23 \\ \text { D02-4a } & & & \end{array}$

$\begin{array}{llllllll}\text { qFOV4- } \quad \text { Mean } & \text { D02 } & 1,386,109 & 1,478,616 & 1,392,442 & 0.33 & 3.71 & -0.11\end{array}$ $D 02-4 b$ 


\begin{tabular}{|c|c|c|c|c|c|c|c|c|}
\hline QTL locus & Test & $\mathrm{Chr}$ & Start (bp) & End (bp) & Peak (bp) & $\begin{array}{l}\text { Mean } \\
\text { SNP } \\
\text { Index }\end{array}$ & $\begin{array}{l}- \\
\log _{10} \\
\text { (p) }\end{array}$ & $\begin{array}{l}\text { Allelic } \\
\text { Effect }\end{array}$ \\
\hline $\begin{array}{l}\text { qFOV4- } \\
\text { D02-5a }\end{array}$ & T1 & D02 & $1,707,229$ & $2,336,933$ & $2,097,862$ & 0.22 & 6.72 & 0.20 \\
\hline $\begin{array}{l}\text { qFOV4- } \\
D 02-5 b\end{array}$ & Mean & D02 & $1,787,329$ & $2,143,747$ & $1,804,734$ & 0.19 & 3.89 & -0.11 \\
\hline $\begin{array}{l}\text { qFOV4- } \\
\text { D02-6a }\end{array}$ & $\mathrm{T} 2$ & D02 & $18,042,939$ & $18,725,840$ & $18,251,131$ & 0.15 & 3.60 & -0.18 \\
\hline $\begin{array}{l}\text { qFOV4- } \\
\text { D02-7a }\end{array}$ & $\mathrm{T} 2$ & D02 & $18,799,231$ & $19,572,947$ & $19,572,947$ & 0.15 & 4.32 & 0.20 \\
\hline $\begin{array}{l}\text { qFOV4- } \\
D 02-7 b\end{array}$ & Mean & D02 & $19,319,469$ & $19,919,667$ & $19,458,775$ & 0.15 & 3.55 & 0.12 \\
\hline $\begin{array}{l}\text { qFOV4- } \\
D 02-7 c\end{array}$ & T2 & D02 & $19,802,857$ & $20,438,501$ & $19,908,316$ & 0.13 & 3.87 & 0.19 \\
\hline $\begin{array}{l}\text { qFOV4- } \\
\text { DO2-8a }\end{array}$ & T2 & D02 & $21,472,314$ & $21,995,058$ & $21,682,186$ & 0.19 & 5.35 & -0.25 \\
\hline $\begin{array}{l}\text { qFOV4- } \\
\text { DO2-8b }\end{array}$ & Mean & D02 & $21,541,506$ & $22,199,752$ & $21,541,506$ & 0.17 & 4.01 & -0.15 \\
\hline $\begin{array}{l}\text { qFOV4- } \\
D 02-8 c\end{array}$ & $\mathrm{~T} 2$ & D02 & $22,119,747$ & $22,794,370$ & $22,697,227$ & 0.19 & 4.07 & -0.22 \\
\hline $\begin{array}{l}\text { qFOV4- } \\
\text { D02-9a }\end{array}$ & $\mathrm{T} 2$ & D02 & $22,843,353$ & $23,250,735$ & $22,988,244$ & 0.19 & 3.65 & 0.20 \\
\hline $\begin{array}{l}\text { qFOV4- } \\
\text { DO3-1 }\end{array}$ & $\mathrm{T} 1$ & D03 & $2,857,159$ & $2,894,575$ & $2,866,837$ & 0.15 & 3.93 & 0.19 \\
\hline $\begin{array}{l}\text { qFOV4- } \\
\text { DO4-1 }\end{array}$ & Mean & D04 & $1,197,145$ & $1,248,176$ & $1,219,821$ & 0.15 & 4.92 & -0.14 \\
\hline $\begin{array}{l}\text { qFOV4- } \\
\text { D11-1 }\end{array}$ & $\mathrm{T} 2$ & D11 & $16,201,083$ & $16,568,089$ & $16,237,920$ & 0.01 & 5.32 & 0.40 \\
\hline $\begin{array}{l}\text { qFOV4- } \\
\text { D11-2 }\end{array}$ & T1 & D11 & $52,964,907$ & $53,368,876$ & $53,302,570$ & 0.09 & 3.71 & 0.19 \\
\hline $\begin{array}{l}\text { qFOV4- } \\
\text { D13-1 }\end{array}$ & $\mathrm{T} 2$ & D13 & $45,707,408$ & $46,211,141$ & $45,957,468$ & 0.41 & 3.49 & -0.15 \\
\hline
\end{tabular}

Two QTLs were detected on each of A12 and D11. However, the common QTL (qFOV4-A12-1) on A12 between Test 2 and the overall means across the two tests was not in proximity ( $9 \mathrm{Mb}$ apart) to the QTL (qFOV4-A12-2) detected in Test 1. The 2 QTLs on D11 detected from Tests 1 and 2 were also different, as they were $37 \mathrm{Mb}$ apart. Interestingly, two QTL clusters with a total of 9 QTLs were declared on D02. The two QTLs (qFOV4-D02-3 and qFOV4-D02-4) were overlapped within a 1.4 Mb interval (at the chromosome position between $0.4-1.8 \mathrm{Mb}$ ), which were only less than $35 \mathrm{~kb}$ away from qFOV4-D02-2 on the left and 
$400 \mathrm{~kb}$ apart from qFOV4-D02-5 on the right. Therefore, these 5 QTLs were clustered. The other 4 QTLs were $5 \mathrm{Mb}$ apart (within the chromosome position 18-23 Mb) and were considered another QTL cluster on the same chromosome.

\section{A meta-analysis of QTL reported for FW resistance in cotton}

A summary of all reported FW resistance QTLs (excluding the ones detected in this current study) on chromosomes is shown in Table 6 and the detailed information from each study is listed in Supplementary Table 1. Of 101 QTLs reported, the D subgenome has significant more (by 59\%) FW resistance $Q T L s$ than the A subgenome (62 vs. $39 ; \chi^{2}=5.24 ; \chi^{2}=3.84, P<0.05$ ). 
Table 6

Distribution of QTL over the 26 tetraploid cotton chromosomes for resistance to Fusarium wilt (Fusarium oxysporum f. sp. vasinfectum) race 4.

\begin{tabular}{|c|c|c|c|}
\hline Chromosome & Zhang et al. (2015) & Abdelraheem et al. (2017) & This study, meta-analysis \\
\hline $\mathrm{c} 1 / \mathrm{A} 01$ & 0 & 0 & 3 \\
\hline $\mathrm{c} 2 / \mathrm{A} 02$ & 0 & 1 & 3 \\
\hline c3/A03 & 1 & 1 & 6 \\
\hline $\mathrm{c} 4 / \mathrm{A} 04$ & 0 & 0 & 0 \\
\hline c5/A05 & 0 & 0 & 0 \\
\hline $\mathrm{c} 6 / \mathrm{A} 06$ & 3 & 6 & 8 \\
\hline c7/A07 & 1 & 1 & 2 \\
\hline C8/A08 & 2 & 4 & 8 \\
\hline C9/A09 & 0 & 0 & 2 \\
\hline c10/A10 & 0 & 0 & 1 \\
\hline c11/A11 & 2 & 4 & 0 \\
\hline c12/A12 & 1 & 2 & 6 \\
\hline c13/A13 & 0 & 0 & 0 \\
\hline A-subgenome & 10 & 19 & 39 \\
\hline c15/D01 & 1 & 1 & 6 \\
\hline c14/D02 & 1 & 2 & 4 \\
\hline c17/D03 & 4 & 5 & 10 \\
\hline c22/D04 & 2 & 3 & 3 \\
\hline c19/D05 & 4 & 8 & 8 \\
\hline c25/D06 & 1 & 2 & 3 \\
\hline c16/D07 & 1 & 1 & 6 \\
\hline c24/D08 & 1 & 2 & 4 \\
\hline c23/D09 & 1 & 0 & 3 \\
\hline c20/D10 & 0 & 0 & 0 \\
\hline c21/D11 & 0 & 0 & 4 \\
\hline c26/D12 & 0 & 0 & 6 \\
\hline
\end{tabular}




\begin{tabular}{|llll|}
\hline Chromosome & Zhang et al. (2015) & Abdelraheem et al. (2017) & This study, meta-analysis \\
\hline c18/D13 & 1 & 4 & 5 \\
\hline D-subgenome & 17 & 28 & 62 \\
\hline Total & 27 & 47 & 101 \\
\hline
\end{tabular}

On an individual chromosome basis, A04, A05, A11, and A13 had no FW resistance QTLs detected, and $A 07, A 09$, and $A 10$ had only 1-2 QTLs reported, while A03, A06, A08, and A12 had the most FW resistance QTLs within the A subgenome. The resistance to FOV4 infections in the two A genome species- G. arboreum and G. herbaceum is inherited as a Mendelian trait (Zhang et al. 2015a); however, thus far, no major gene or QTL for FOV4 resistance has been reported on the A subgenome. Du et al. (2018) reported a main-effect QTL on chromosome c11 (A11) for FOV7 resistance based on GWAS using 215 Chinese $G$. arboreum accessions. However, it is currently unclear whether this QTL confers resistance to FOV4. On the D subgenome, only D10 did not have reported QTLs for FW resistance, and all other chromosomes carried 3 or more FW resistance QTLs including D01, D03, D05, D07, D12, and D13 with 5 or more QTLs detected. Therefore, overall, the D subgenome harbors more QTLs for resistance to FW, and the FW resistance QTLs were not evenly distributed on the tetraploid cotton chromosomes. Furthermore, the chromosomes with more QTLs detected are not necessarily the ones possessing a major gene/QTL for FW resistance including FOV1 on D07 (c16), FOV4 on D02 (c14), FW' $W^{R}$ D03 (c17), and an unnamed gene on D11 (c21).

On a homeologous chromosome pair basis, the two pairs (A03/D03 and A12/D12) had more QTLs detected, while A10/D10 had almost no QTL reported among the 13 pairs. A06 and A08 had 2-2.7 times more QTLs detected than their homeologous counterparts (D06 and D08), respectively. However, D01, D03, D04, D05, D07, D11, and D13 carried 1.7 times or more QTLs than their homeologous A subgenome counterparts, respectively. Overall, there was no significant positive correlation $(r=0.153, P>0.05)$ in the number of FW resistance QTLs between the 13 pairs of homeologous chromosomes, suggesting different mechanisms evolved from the two subgenomes to fight FOV infections in tetraploid cotton.

\section{Identification Of Candidate Genes For Fw Resistance QtI}

In this study, a total of 532 genes were identified within the 23 QTL regions declared, of which 198 genes were found to have non-synonymous SNPs among the 11 parents. Based on the concept that these parental SNP should be reflected in RILs with different responses to FOV4, SNP indexes were further calculated between two groups (resistant vs. susceptible) of the selected RILs, as shown in Table 4. An average SNP index within each QTL region is shown in Table 5. Only these genes with a SNP index of 0.3 or higher were considered as candidates for the QTL. As a result, 48 genes met all the criteria, most of which were located on D02 and 15 genes were related to defenses to fungi (Supplementary Table 2). Interestingly, the major FOV4-resistance QTL locus qFOV4-D02-3 (with peak LOD scores greater than the FDR of $1.056 \times 10^{-7}$ at the $0.92-0.98 \mathrm{Mb}$ region) contained 14 candidate genes, three of which 
(Gh_D02G0105, Gh_D02G0115, and Gh_D02G0119) responded to fungal infections (Supplementary Table 2). More studies are needed to narrow candidate genes for the QTL.

\section{Discussion}

FW caused by FOV is one of the most important soil-borne fungal diseases affecting world cotton production. Numerous studies have investigated the genetic basis of FW resistance using bi-parental or association mapping populations, resulting in more than 100 QTLs reported, as summarized in this study. However, no multi-parent populations were developed and used for identification of genes or QTLs for resistance to FW. In this study, we evaluated a MAGIC population of 550 RILs derived from intermating of 11 American Upland cotton parents representing major US seed companies and public cotton breeding programs. Through artificial inoculation in two replicated tests in the greenhouse, significant genotypic variation among the parents and within the RILs was detected, allowing estimation of broad-sense heritability (0.62). The result was consistent with our previous greenhouse studies (Abdelraheem et al. 2020a; Zhang et al. 2020b). Based on almost half a million polymorphic SNPs, 23 QTLs (7 on the Asubgenome and 16 on the D- subgenome) including one major QTL on D02 for FOV4 resistance were detected on 12 of the 26 pairs of Upland cotton chromosomes. The narrow chromosomal region at an 0.2 $\mathrm{Mb}$ interval (at 0.79-0.98 $\mathrm{Mb}$ with the peak at 0.92-0.98 Mb) for the major resistance QTL on D02 allowed identification of 14 possible candidate genes for FOV4 resistance. This study represents the first report using a MAGIC population with currently the largest number of RILs for mapping QTLs conferring resistance to FW in cotton. The results will be useful to both marker-assisted selection and further studies towards cloning of candidate genes for FW resistance QTLs. Furthermore, the results from this current study allow discussion of several important issues facing genomic studies of resistance to FW in the cotton community.

\section{Quantitative Or Qualitative Resistance To Fov4 In Cotton}

FW caused by FOV4 under field conditions is an early season disease with high seedling mortality (Zhang et al. 2020b). In this study, no parents including the most susceptible ones achieved high levels of mortality and DSR because of the high temperature conditions in the greenhouse when the parents and MAGIC RILs were evaluated for FOV4 resistance. This is consistent with Zhang et al. (2020b) that very low seedling mortality was observed in more than 2,000 lines evaluated under high temperature ranges $\left(26-32^{\circ} \mathrm{C}\right)$ in the greenhouse. However, high mortality including $100 \%$ mortality (i.e., with DSR of 5 ) in $50 \%$ of the 1,200 germplasm lines evaluated were observed under low temperature $\left(20-21^{\circ} \mathrm{C}\right.$ ) settings (Zhang et al. 2020b). Responses of the 11 parents to FOV4 infections under the low temperature conditions may be different, and they may have high seedling death rates. Zhang et al. (2020b) suggested that the low temperature conditions allow detection of high levels of qualitative FOV4 resistance, while the high temperature conditions detect low levels of quantitative resistance to FOV4. Zhang et al. (2021) confirmed that FW caused by FOV4 is a temperature dependent disease with an optimal temperature of $22-23^{\circ} \mathrm{C}$ to cause mortality. Equally importantly, FW caused by FOV4 is also inoculum density dependent. 
Hao et al. (2009) showed that FW symptoms and plant growth reductions began at the inoculum density of $10^{3}$ FOV4 conidia $\mathrm{g}^{-1}$ of potting mix in highly susceptible Pima cultivar DP744 and moderately susceptible Upland Acala Ultima. However, they increased more rapidly in the former and reached the plateau at the inoculum level of $10^{5} \mathrm{FOV} 4$ conidia $\mathrm{g}^{-1}$ of soil, whereas the increase in disease severity and decrease in plant growth did not reach plateau in the latter even at the inoculum level of $10^{6} \mathrm{FOV} 4$ conidia $\mathrm{g}^{-1}$ of soil. Therefore, optimal disease development conditions play an important role in determining if a genotype possesses a qualitative resistance to FOV4.

Qualitative or quantitative resistance is genotype dependent. In many studies on resistance to FW in cotton, evaluations of plant responses to FOV infections were conducted under natural infested field conditions. In other cases, artificial inoculation and evaluation may not be under optimal environmental conditions for FW disease development. Furthermore, low FOV inoculum density and non-uniformity of FOV inoculum in the soil under field conditions did not allow reliable separation of true resistance from escapes and differentiation of quantitative differences in resistance on an individual plant basis. As such, resistance to $\mathrm{FW}$ is often treated as a quantitative trait with low to moderate heritabilities estimated (Zhang et al. 2015). An example is the Chinese Upland resistant cultivars to FOV7. When high and unform inoculum density of FOV7 spores was provided, heritabilities for resistance were $>0.9$ with only one resistance gene estimated based on a diallel cross mating design (Zhang et al. 1994; Feng et al. 1998). When the same inoculum method was used to evaluate $F_{2}$ and backcross generations, a typical Mendelian segregation ratio (3:1 or 1:1) was observed. Therefore, for genotypes with high and qualitative resistance, identification of a major resistance gene is dependent on both high and uniform inoculum density under optimal environmental conditions for FW disease development.

\section{Subgenome Bias Of Qtl Distribution For Disease Resistance}

Through a meta-analysis of published 101 QTLs for FW resistance in cotton, this study showed a significant D-subgenome bias of FW disease resistance QTLs, which is consistent with the findings of resistance QTLs for bacterial blight (BB, caused by Xanthomonas citri pv. malvacearum (Wright et al. 1998) and Verticillium wilt (VW, Abdelraheem et al. 2017). Wright et al. (1998) mapped 5 (83\%) of the 6 resistance QTLs for BB resistance to the D subgenome. In a meta-analysis, Abdelraheem et al. (2017) found that significantly more reported QTLs (118) for VW resistance were mapped to the D subgenome than the A subgenome (83). However, the reverse was true for resistance to RKN and reniform nematodes (Rotylenchulus reniformis) with 55 and 30 QTLs on the A and D subgenomes, respectively. Therefore, whether the $\mathrm{D}$ subgenome evolves new $\mathrm{R}$ genes or resistance QTLs more rapidly than the $\mathrm{A}$ subgenome or vice versa depends on pathogen after the two ancestral diploid genomes were merged into the same nucleus during the origin of the tetraploid cotton.

\section{Comparison Of Major Qtls Mapped For Fov Resistance}


In this study, we have mapped a major FOV4-resistance QTL close to the telomere on one chromosome arm of D2. This QTL region was close to the RKN-resistant Mi2 gene (Gh_D02G0276 at $3.45 \mathrm{Mb}$ ) (Wubben et al. 2019). Therefore, it appeared that the FOV4-resistance QTL and the RKN-resistance QTL locus were located toward the telomere of the chromosome and closely linked (ca. $2.5 \mathrm{Mb}$ apart). Recently, a major effect QTL for FOV4 resistance in NemX was also mapped to the same chromosome (D02) but on the other terminal (at 69.48-69.58 Mb) anchored by two SSR markers (BNL3932 and DPL0473 with $1.2 \mathrm{cM}$ and $0.1 \mathrm{Mb}$ apart) and another SSR marker MUSB0850 within a $30.7 \mathrm{cM}$ region using a RIL population of 90 lines (Wang et al. 2018). However, due to the limited number of SSR markers and RILs used, the mapping resolution was too rough to delineate the QTL region. This QTL was in a QTL cluster with another major-effect QTL for FOV4 resistance within the 58-63 Mb region identified most recently by Abdelraheem et al. (2020a) using 376 US Upland cotton accessions and 25,677 SNP markers. However, within this chromosome region, we did not detect any FOV4 resistance QTL in our current study. Previously, a major FOV4-resistance gene in Pima S-6 was mapped to D02 by Ulloa et al. (2013), but the DNA sequence for the anchoring SSR marker BNL0834 is contained in D03 (c17) at $8.2 \mathrm{Mb}$. Therefore, the exact chromosomal location of this major FOV4 resistance gene is currently unknown and should be further investigated. Interestingly, Liu et al. (2021) have recently reported the identification of Gh_D03G0209 (named GhGLR4.8) on D03 encoding a GLUTAMATE RECEPTOR-LIKE (GLR) protein as the candidate gene for the resistance gene Fov7 with resistance to FOV race 7 through a GWAS using 290 Chinese Upland accessions. CRISPR/Cas9-mediated knockout of the Fov7 gene confirmed that a SNP $(\mathrm{C} / \mathrm{A})$ in the gene, leading to an amino acid change (L/I) in the enzyme, is responsible for FOV7 resistance. However, neither Gh_D03G0209, nor its A-subgenome homeolog Gh_A02G1505 were located in the vicinity of the QTLs reported in this study. This small gene family does not appear to have any other obvious members.

Based on GWAS using 215 Chinese $G$. arboreum accessions with 1.4 million resequencing-based SNP markers, Du et al. (2018) identified the candidate gene Ga11G2353 encoding for a glutathione Stransferase (GaGSTF9) for a major-effect QTL on chromosome A11 (within 1.0 Mb interval in the 102.5$103.5 \mathrm{Mb}$ region) for FOV7 resistance. Its homologous gene in Upland cotton is Gh_A11G1459; however, no QTL on A11 for FOV4 resistance was identified in our current study and for other FOV races in previous studies. In addition, similar to previous studies, we detected fewer QTLs for FOV resistance on the A subgenome than on the $D$ subgenome. Therefore, the genetic bases (in terms of QTL numbers and locations) for FOV resistance between the diploid $A$ genome and the tetraploid $A D$ genome appeared different. However, interestingly, the D-subgenome homeolog, Gh_D11G1615 is located within 1-Mb of the QTL on D11 we named qFOV4-D11-1. Three other genes with significant homology to Ga11G2353 (Gh_A11G1459) were also observed near the presently described QTLs: Gh_D11G1496 at qFOV4-D11-1, Gh_D13G1398 at qFOV4-D13-1 and Gh_D01G1754 at qFOV4-D01-1 and are worthy of further investigations.

\section{Difficulty in delineating major QTLs for FW resistance and solutions}


It appears that neither Ga11G2353 nor Gh_D03G0209 belongs to typical plant resistance genes (i.e., Rgenes) coding for molecules essential for pathogen defense including pattern recognition receptors (PRRs), wall associated kinase (WAKs), receptors with nucleotide-binding domain (NLRs) and leucine-rich repeats (LRRs). It should be recognized that the resolution power from 200-300 accessions or genotypes in a genetic population is usually not high enough for high resolution mapping to pinpoint a candidate gene, because a $0.3-0.5 \mathrm{cM}$ chromosome region may still contain 5-10 or more genes, regardless of the number of SNP markers. Based on almost half a million SNPs and 550 MAGIC lines, this current study identified a major resistance QTL within the $0.72-0.98 \mathrm{Mb}$ region which still contains 14 genes. Furthermore, it is often true that numerous germplasm accessions used were not homozygous as evidenced from various percentages of heterogeneous and heterozygous SNP markers and segregation in phenotypes including FOV resistance within the same accessions (Zhang et al. 2020b). The lack of purity of germplasm lines used and high experimental errors in phenotyping cotton for FOV resistance further compromised the accuracy and precision in QTL mapping location and subsequent identification of candidate genes. Therefore, to reliably map and clone FOV-resistant QTL or genes, homozygous lines (accessions) from a large genetic population (1,000-2,000 genotypes) should be developed and employed in multiple replicated tests; and a reliable artificial inoculation and screening method for FOV resistance should be established and used.

\section{Author contribution statement}

J. Z. conceived and designed the study. Y. Z., G. T. and J. Z. drafted the manuscript. Y. Z., A. A. and Z. T. performed the phenotyping experiment and analyzed the data. G. T. and D. F. developed the SNP markers. G. T. performed the GWAS and identified QTLs and candidate genes. J. J. and J. M. developed the MAGIC population. T. W. and H. H. supported the study. All authors read and approved the final version of the manuscript.

\section{Declarations}

\section{Author contribution statement}

J. Z. conceived and designed the study. Y. Z., G. T. and J. Z. drafted the manuscript. Y. Z., A. A. and Z. T. performed the phenotyping experiment and analyzed the data. G. T. and D. F. developed the SNP markers. G. T. performed the GWAS and identified QTLs and candidate genes. J. J. and J. M. developed the MAGIC population. T. W. and H. H. supported the study. All authors read and approved the final version of the manuscript.

\section{Corresponding author}

Correspondence to Jinfa Zhang, jinzhang@nmsu.edu.

\section{Data availability}

Except for the supplementary tables, no other data is available. 


\section{Conflict of interests}

The authors declare that they have no conflict of interest.

\section{Ethical approval}

Not applicable.

\section{References}

1. Abdelraheem A, Fang DD, Dever J, Zhang JF (2020b) QTL analysis of agronomic, fiber quality, and abiotic stress tolerance traits in a recombinant inbred population of pima cotton. Crop Sci 60:18231843

2. Abdelraheem A, Fang DD, Zhang JF (2018) Quantitative trait locus mapping of drought and salt tolerance in an introgressed recombinant inbred line population of Upland cotton under the greenhouse and field conditions. Euphytica 214:1-20

3. Abdelraheem A, Kuraparthy V, Hinze L, Stelly S, Zhang JF (2020a) A genome-wide association study uncovers consistent quantitative trait loci for resistance to Verticillium wilt and Fusarium wilt in the U.S. Upland cotton. Theor Appl Genet 133:563-577

4. Abdelraheem A, Liu F, Song M, Zhang JF (2017) A meta-analysis of quantitative trait loci for abiotic and biotic stress resistance in tetraploid cotton. Mol Genet Genom 292:1221-1235

5. Atwell S, Huang YS, Vilhjálmsson BJ, Willems G, Horton M, Li Y, Meng D, Platt A, Tarone AM, Hu TT, Jiang R (2010) Genome-wide association study of 107 phenotypes in Arabidopsis thaliana inbred lines. Nature 465:627-631

6. Bell AA, Gu A, Olvey J, Wagner TA, Tashpulatov JJ, Prom S, Quintana J, Nichols RL, Liu J (2019) Detection and characterization of Fusarium oxysporum f. sp. vasinfectum VCG0114 (Race 4) isolates of diverse geographic origins. Plant Dis 103:1998-2009

7. Benjamini Y, Hochberg Y (1995) Controlling the false discovery rate: a practical and powerful approach to multiple testing. J R Statist Soc B 57:289-300

8. Berardini TZ, Reiser L, Li D, Mezheritsky Y, Muller R, Strait E, Huala E (2015) The Arabidopsis information resource: making and mining the "gold standard" annotated reference plant genome. Genetics 53:474-485

9. Bird LS (1982) The MAR (multi-adversity resistance) system for genetic improvement of cotton. Plant Dis $66: 172-176$

10. Blasingame D, Patel MV (2013) Cotton disease loss estimate committee report. In: Proceedings of the Beltwide cotton conference, National Cotton Council, Memphis, TN, pp 1242-1245

11. Bourland FM (1996) Registration of 'H1330' cotton. Crop Sci 36:813

12. Cianchetta AN, Allen TW, Hutmacher RB, Kemerait RC, Kirkpatrick TL, Lawrence GW, Lawrence KS, Mueller JD, Nichols RL, Olsen MW, Overstreet C, Woodward JE, Davis RM (2015) Survey of Fusarium 
oxysporum f. sp. vasinfectum in the United States. J Cotton Sci 19:328-336

13. Davis RM, Colyer PD, Rothrock CS, Kochman JK (2006) Fusarium wilt of cotton: Population diversity and implications for management. Plant Dis 90:692-703

14. Du X, Huang G, He S, Yang Z, Sun G, Ma X, Li N, Zhang X, Sun J, Liu M, Jia Y, Pan Z, Gong W, Liu Z, Zhu H, Ma L, Liu F, Yang D, Wang F, Fan W, Gong Q, Peng Z, Wang L, Wang X, Xu S, Shang H, Lu C, Zheng H, Huang S, Lin T, Zhu Y, Li F (2018) Resequencing of 243 diploid cotton accessions based on an updated $A$ genome identifies the genetic basis of key agronomic traits. Nat Genet 50:796-802

15. Fahmy T (1934) The selection of wilt immune strains of long staple cotton (Sakha 4 Gidid). Egypt Ministry Agric Techn Sci Serv Bull 130

16. Feng CD, Zhang JF, Liu JL, Wu ZB, Guo JH, Sun JZ (1998) Allelism and linkage test of upland cotton genes resistant to Fusarium wilt. Hereditas 20:33-36

17. Gutiérrez OA, Jenkins JN, McCarty JC, Wubben MJ, Hayes RW, Callahan FE (2010) SSR markers closely associated with genes for resistance to root-knot nematode on chromosomes 11 and 14 of Upland cotton. Theor Appl Genet 121:1323-1337

18. Halpern HC, Bell AA, Wagner TA, Liu J, Nichols RL, Olvey J, Woodward JE, Sanogo S, Jones CA, Chan CT, Brewer MT (2018) First report of Fusarium wilt of cotton caused by Fusarium oxysporum $\mathrm{f}$. sp. vasinfectum race 4 in Texas, U.S.A. Plant Dis 102:446

19. Hao JJ, Yang ME, Davis RM (2009) Effect of soil inoculum density of Fusarium oxysporum $\mathrm{f}$. sp. vasinfectum race 4 on disease development in cotton. Plant Dis 93:1324-1328

20. He Y, Kumar P, Shen X, Davis RF, Becelaere GV, May OL, Nichols RL, Chee PW (2014) Re-evaluation of the inheritance for root-knot nematode resistance in the Upland cotton germplasm line M-120 RNR revealed two epistatic QTLs conferring resistance. Theor Appl Genet 127:1343-1351

21. Hu Y, Chen J, Fang L, Zhang Z, Ma W, Niu Y, Ju L, Deng J, Zhao T, Lian J, Baruch K, Fang D, Liu X, Ruan YL, Rahman MU, Han J, Wang K, Wang Q, Wu H, Mei G, Zang Y, Han Z, Xu C, Shen W, Yang D, Si Z, Dai F, Zou L, Huang F, Bai Y, Zhang Y, Brodt A, Ben-Hamo H, Zhu X, Zhou B, Guan X, Zhu S, Chen X, Zhang T (2019) Gossypium barbadense and Gossypium hirsutum genomes provide insights into the origin and evolution of allotetraploid cotton. Nat Genet 51:739-748

22. Huang C, Nie X, Shen C, You C, Li W, Zhao W, Zhang X, Lin Z (2017) Population structure and genetic basis of the agronomic traits of upland cotton in China revealed by a genome-wide association study using high-density SNPs. Plant Biotechnol J 15:1374-1386

23. Huang C, Shen C, Wen T, Gao B, Zhu D, Li X, Ahmed MM, Li D, Lin Z (2018) SSR-based association mapping of fiber quality in upland cotton using an eight-way MAGIC population. Mol Genet Genom 293:793-805

24. Hutmacher RB, Ulloa M, Wright SD, Campbell BT, Percy RG, Wallace T, Myers G, Bourland F, Weaver D, Chee P, Thaxton P, Zhang J, Smith W, Dever J, Kuraparthy V, Bowman D, Jones D, Burke J (2013) EliteUpland cotton germplasm-pool assessment of Fusarium wilt resistance in California. Agron $\mathrm{J}$ 105:1635-1644 
25. Islam MS, Thyssen GN, Jenkins JN, Fang DD (2015) Detection, validation, and application of genotyping-by-sequencing based single nucleotide polymorphisms in upland cotton. The Plant Genome 8:1-10

26. Islam MS, Thyssen GN, Jenkins JN, Zeng L, Delhom CD, McCarty JC, Deng DD, Hinchliffe DJ, Jones DC, Fang DD (2016) A MAGIC population-based genome-wide association study reveals functional association of GhRBB1_A07 gene with superior fiber quality in cotton. BMC Genom 17:1-17

27. Jenkins JN, McCarty JC, Gutierrez OA, Hayes RW, Bowman DT, Watson CE, Jones DC (2008) Registration of RMUP-C5, a random mated population of Upland cotton germplasm. J Plant Reg 2:239-244

28. Kappelman AJ Jr, Bird LS (1981) Indirect selection for resistance to the fusarium wilt-root-knot nematode complex in cotton. Crop Sci 21:66-68

29. Kim Y, Hutmacher RB, Davis RM (2005) Characterization of California isolates of Fusarium oxysporumf. sp. vasinfectum. Plant Dis 89:366-372

30. Kump KL, Bradbury PJ, Wisser RJ, Buckler ES, Belcher AR, Oropeza-Rosas MA, Zwonitzer JC, Kresovich S, McMullen MD, Ware D, Balint-Kurti PJ (2011) Genome-wide association study of quantitative resistance to southern leaf blight in the maize nested association mapping population. Nature Genet 43:163-168

31. Li H, Handsaker B, Wysoker A, Fennell T, Ruan J, Homer N, Marth G, Abecasis G, Durbin R (2009) The sequence alignment/map format and SAMtools. Bioinformatics 25:2078-2079

32. Li T, Ma X, Li N, Zhou L, Liu Z, Han H, Gui Y, Bao Y, Chen J, Dai X (2017) Genome-wide association study discovered candidate genes of Verticillium wilt resistance in upland cotton (Gossypium hirsutum L.). Plant Biotechnol J 15:1520-1532

33. Lipka AE, Tian F, Wang Q, Peiffer J, Li M, Bradbury PJ, Gore MA, Buckler ES, Zhang Z (2012) GAPIT: genome association and prediction integrated tool. Bioinformatics 28:2397-2399

34. Liu R, Gong J, Xiao X, Zhang Z, Li J, Liu A, Lu Q, Shang H, Shi Y, Ge Q, Iqbal MS (2018) GWAS analysis and QTL identification of fiber quality traits and yield components in upland cotton using enriched high-density SNP markers. Front Plant Sci 9:1067

35. Liu S, Zhang X, Xiao S, Ma J, Shi W, Qin T, Xi H, Nie X, You C, Xu Z, Wang T, Wang Y, Zhang Z, Li J, Kong J, Aierxi A, Yu Y, Lindsey K, Klosterman SJ, Zhang X, Zhu L (2021) A single-nucleotide mutation in a GLUTAMATE RECEPTOR-LIKE gene confers resistance to fusarium wilt in Gossypium hirsutum. Adv Sci 8:2002723

36. Naoumkina M, Thyssen GN, Fang DD, Jenkins JN, McCarty JC, Florane CB (2019) Genetic and transcriptomic dissection of the fiber length trait from a cotton (Gossypium hirsutum L.) MAGIC population. BMC Genom 20:112

37. Netzer D (1982) Resistance to Fusarium oxysporum: Inheritance in watermelon and cotton and mechanism in cotton. Phytoparasitica 10:131

38. Nie X, Huang C, You C, Li W, Zhao W, Shen C, Zhang B, Wang H, Yan Z, Dai B, Wang M (2016) Genome-wide SSR-based association mapping for fiber quality in nation-wide upland cotton inbreed 
cultivars in China. BMC Genom 17:1-16

39. Niu C, Hinchliffe DJ, Cantrell RG, Wang C, Roberts PA, Zhang JF (2007) Identification of molecular markers associated with root-knot nematode resistance in Upland cotton. Crop Sci 47:951-960

40. Qin H, Chen M, Yi X, Bi S, Zhang C, Zhang Y, Lan J, Meng Y, Yuan Y, Jiao C (2015) Identification of associated SSR markers for yield component and fiber quality traits based on frame map and upland cotton collections. PloS one 10:e0118073

41. Sanogo S, Zhang JF (2016) Resistance sources, resistance screening techniques and disease management for Fusarium wilt in cotton. Euphytica 207:255-271

42. Smith AL, Dick JB (1960) Inheritance of resistance to Fusarium wilt in Upland and Sea Island Cottons as complicated by nematodes under field conditions. Phytopathology 50:44-48

43. Smith CW (1988) Registration of 'Arkot 518' upland cotton. Crop Sci 28:190

44. Takagi H, Abe A, Yoshida K, Kosugi S, Natsume S, Mitsuoka C, Uemura A, Utsushi H, Tamiru M, Takuno S, Innan H, Cano LM, Kamoun S, Terauchi R (2013) QTL-seq: rapid mapping of quantitative trait loci in rice by whole genome resequencing of DNA from two bulked populations. Plant J 74:174-183

45. Thaxton PM, El-Zik KM (1998) Host plant resistance to pathogens in MAR cotton germplasm. In Proceedings World Cotton Research Conference-2, Athens, Greece.pp. 113-119

46. Thaxton PM, El-Zik KM (2003) Registration of eleven multi-adversity resistant (MAR-7a) germplasm lines of upland cotton. Crop Sci 43:741-743

47. Thaxton PM, El-Zik KM (2004a) Registration of 'Tamcot Pyramid' cotton. Crop Sci 44:343-344

48. Thaxton PM, El-Zik KM (2004b) Registration of eight multi-adversity resistant (MAR-7B) germplasm lines of upland cotton. Crop Sci 44:1494-1496

49. Thyssen GN, Jenkins JN, McCarty JC, Zeng L, Campbell BT, Delhom CD, Islam MS, Li P, Jones DC, Condon BD, Fang DD (2019) Whole genome sequencing of a MAGIC population identified genomic loci and candidate genes for major fiber quality traits in upland cotton (Gossypium hirsutum L.). Theor Appl Genet 132:989-999

50. Ulloa M, Hutmacher RB, Roberts PA, Wright SD, Nichols RL, Davis RM (2013) Inheritance and QTL mapping of Fusarium wilt race 4 resistance in cotton. Theor Appl Genet 126:1405-1418

51. Ulloa M, Wang C, Hutmacher RB, Wright SD, Davis RM, Saski CA, Roberts PA (2011) Mapping Fusarium wilt race 1 resistance genes in cotton by inheritance, QTL and sequencing composition. Mol Genet Genom 286:21-36

52. Wang C, Roberts PA (2006) A Fusarium wilt resistance gene in Gossypium barbadense and its effect on root-knot nematode-wilt disease complex. Phytopathology 96:727-734

53. Wang C, Ulloa M, Duong T, Roberts PA (2018) QTL mapping of multiple independent loci for resistance to Fusarium oxysporum $\mathrm{f}$. sp. vasinfectum races 1 and 4 in an interspecific cotton population. Phytopathology 108:759-767 
54. Wang M, Tu L, Yuan D, Zhu L, Shen C, Li J, Liu F, Pei L, Wang P, Zhao G, Ye Z, Huang H, Yan F, Ma Y, Zhang L, Liu M, You J, Yang Y, Liu Z, Huang F, Li B, Qiu P, Zhang Q, Zhu L, Jin S, Yang X, Min L, Li G, Chen LL, Zheng H, Lindsey K, Lin Z, Udall JA, Zhang X (2019) Reference genome sequences of two cultivated allotetraploid cottons, Gossypium hirsutum and Gossypium barbadense. Nat Genet 51:224-229

55. Wang P, Su L, Qin L, Hu B, Guo W, Zhang T (2009) Identification and molecular mapping of Fusarium wilt resistant gene in upland cotton. Theor Appl Genet 119:733-739

56. Wright RJ, Thaxton PM, El-Zik KM, Paterson AH (1998) D-subgenome bias of Xcm resistance genes in tetraploid Gossypium (cotton) suggests that polyploid formation has created novel avenues for evolution. Genetics 149:1987-1996

57. Wu TD, Nacu S (2010) Fast and SNP-tolerant detection of complex variants and splicing in short reads. Bioinformatics 26:873-881

58. Wubben MJ, Thyssen GN, Callahan FE, Fang DD, Deng DD, McCarty JC, Li P, Islam MS, Jenkins JN (2019) A novel variant of Gh_D02G0276 is required for root-knot nematode resistance on chromosome 14 (D02) in Upland cotton. Theor Appl Genet 132:1425-1434

59. You Q, Xu W, Zhang K, Zhang L, Yu X, Yao D, Wang C, Zhang X, Zhao X, Provart NJ (2016) ccNET: Database of co-expression networks with function modules for diploid and polyploid Gossypium. Nucleic Acids Res 45:D1090-D1099

60. Zhang JF, Abdelraheem A, Thyssen G, Fang DD, Jenkins J, McCarty JC, Wedegaertner T (2020a) Evaluation and genome-wide association study of Verticillium wilt resistance in a MAGIC population derived from intermating of 11 Upland cotton (Gossypium hirsutum) parents. Euphytica 216:9

61. Zhang JF, Abdelraheem A, Zhu Y, Wheeler TA, Dever JK, Frelichowski J, Love J, Ulloa M, Jenkins JN, McCarty JC Jr, Nichols R, Wedegaertner T (2020b) Assessing genetic variation for Fusarium wilt race 4 resistance in tetraploid cotton by screening over three thousand germplasm lines under greenhouse or controlled conditions. Euphytica 216:106

62. Zhang JF, Abdelraheem A, Zhu Y, Wheeler TA, Dever JK, Nichols R, Wedegaertner T (2021) Importance of temperature in evaluating cotton for resistance to Fusarium wilt caused by Fusarium oxysporum $\mathrm{f}$. sp. vasinfectum race 4. Crop Sci 61:1783-1796

63. Zhang JF, Sanogo S, Flynn R, Baral JB, Bajaj S, Hughs SE, Percy RG (2012) Germplasm evaluation and transfer of Verticillium wilt resistance from Pima (Gossypium barbadense) to Upland cotton (G. hirsutum). Euphytica 187:147-160

64. Zhang JF, Sanogo S, Ma ZY, Qu YY (2015a) Breeding, genetics, and quantitative trait locus mapping for Fusarium wilt resistance in cotton. Crop Sci 55:2435-2453

65. Zhang JF, Yu J, Pei W, Li X, Said J, Song M, Sanogo S (2015b) Genetic analysis of Verticillium wilt resistance in a backcross inbred line population and a meta-analysis of quantitative trait loci for disease resistance in cotton. BMC Genom 16:577

66. Zhang JF, Zhu Y, Abdelraheem A, Lujan P, Idowu J, Nichols R, Wedegaertner T (2020c) Field survey, detection and characterization of Fusarium wilt race 4 in cotton in New Mexico. Proceedings of the 
Beltwide Cotton Conference. p. 84

67. Zhang T, Hu Y, Jiang W, Fang L, Guan X, Chen J, Zhang J, Saski CA, Scheffler BE, Stelly D, HulseKemp AM et al (2015) Sequencing of allotetraploid cotton (Gossypium hirsutum L. acc. TM-1) provides a resource for fiber improvement. Nat Biotechnol 33:531-537

68. Zhang Z, Ersoz E, Lai C-Q, Todhunter RJ, Tiwari HK, Gore MA, Bradbury PJ, Yu J, Arnett DK, Ordovas JM et al (2010) Mixed linear model approach adapted for genome-wide association studies. Nat Genet 42:355

69. Zhao K, Tung CW, Eizenga GC, Wright MH, Ali ML, Price AH, Norton GJ, Islam MR, Reynolds A, Mezey J, McClung AM (2011) Genome-wide association mapping reveals a rich genetic architecture of complex traits in Oryza sativa. Nat Commun 2:1-10

70. Zhao X, Han Y, Li Y, Liu D, Sun M, Zhao Y, Lv C, Li D, Yang Z, Huang L, Teng W (2015) Loci and candidate gene identification for resistance to Sclerotinia sclerotiorum in soybean (Glycine max $\mathrm{L}$. Merr.) via association and linkage maps. Plant J 82:245-255

71. Zhao Y, Chen W, Cui Y, Sang X, Lu J, Jing H, Wang W, Zhao P, Wang H (2021) Detection of candidate genes and development of KASP markers for Verticillium wilt resistance by combining genome-wide association study, QTL-seq and transcriptome sequencing in cotton. Theor Appl Genet 134:10631081

72. Zhu Y, Abdelraheem A, Lujan P, Idowu OJ, Sullivan P, Nichols R, Wedegaertner T, Zhang JF (2021) Detection and characterization of Fusarium wilt (Fusarium oxysporum $\mathrm{f}$. sp. vasinfectum) race 4 causing Fusarium wilt of cotton seedlings in New Mexico, USA. Plant Dis. Published Online: 5 Feb 2021https://doi.org/10.1094/PDIS-10-20-2174-RE

73. Zhu Y, Abdelraheem A, Teng ZH, Sanogo S, Wheeler T, Wedegaertner T, Zhang JF (2019) Pathogenicity test of Fusarium wilt and screening germplasm lines for Fusarium wilt resistance in cotton. Proceedings of the Beltwide Cotton Conference, p.15

74. Zhu Y, Abdelraheem A, Wheeler TA, Dever JK, Wedegaertner T, Hake KD, Zhang JF (2021) Interactions between cotton genotypes and Fusarium wilt race 4 isolates from Texas and resistance evaluation in cotton. Crop Sci 61:1809-1825

75. Zhu Y, Lujan PA, Wedegaertner T, Nichols R, Abdelraheem A, Zhang JF, Sanogo S (2020) First report of Fusarium oxysporum f. sp. vasinfectum race 4 causing Fusarium wilt of cotton in New Mexico, USA. Plant Dis 104:588

76. Zhu YJ, Zhang XY, Li JR, Han L, Zhang W (2010) Inheritance of resistance to Fusarium wilt and their molecular marker in Gossypium barbadense (In Chinese with English abstract). Xinjiang Agric Sci $2: 268-273$

\section{Figures}




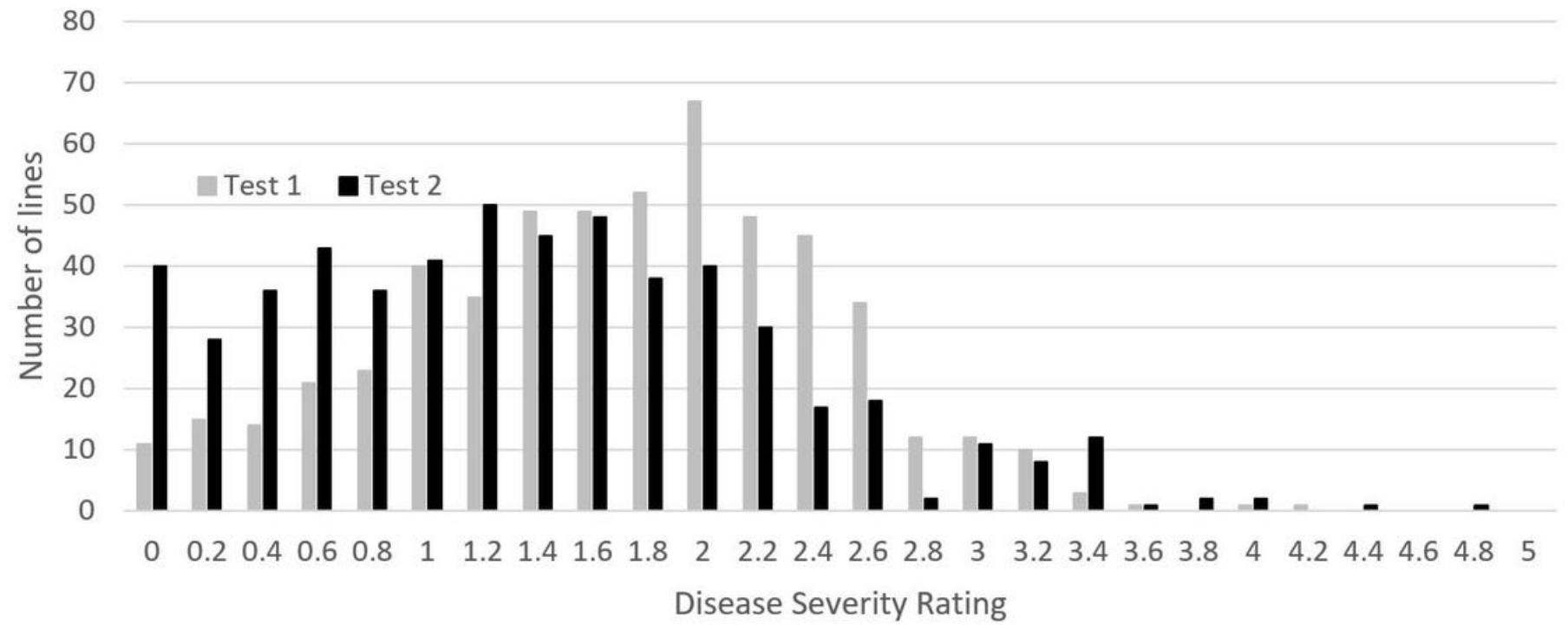

Figure 1

Fusarium wilt (Fusarium oxysporum f. sp. vasinfectum) race 4 resistance (based on severity disease ratings) of 550 recombinant inbred lines (Gossypium hirsutum) in the MAGIC population tested in two replicated tests with artificial inoculations in the greenhouse, Las Cruces, NM, USA. 

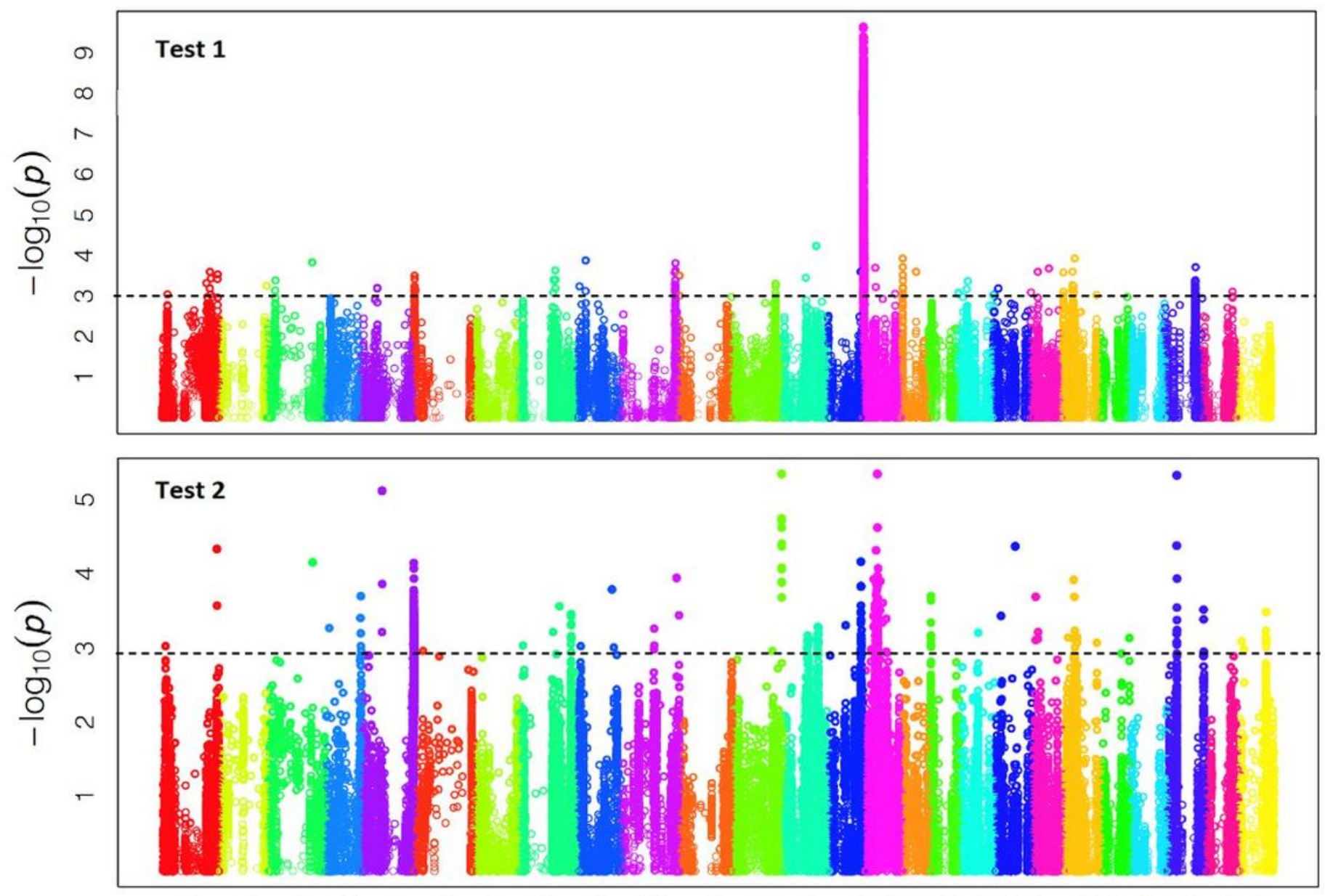

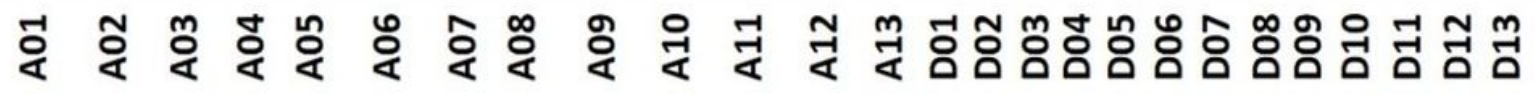

Figure 2

A Manhattan plot showing chromosomal regions with Fusarium wilt race 4 (Fusarium oxysporum f. sp. vasinfectum) resistance QTL based on severity disease ratings identified as indicated by an arrow in a MAGIC population of 550 recombinant inbred lines (Gossypium hirsutum).

\section{Supplementary Files}

This is a list of supplementary files associated with this preprint. Click to download.

- CottonFWQTLSummarySupplTable1.xlsx

- MAGICRILFOV4GWASSuppITable2.xIsx 